\title{
Antioxidant properties of selected mango varieties and correlation with the shelf-life of their products
}

\author{
S. M. M. Kabir ${ }^{1 *}$, A. Alam ${ }^{1}$ and B. Uddin ${ }^{2}$ \\ ${ }^{1}$ Department of Chemistry, Rajshahi University of Engineering and Technology, Rajshahi, Bangladesh \\ ${ }^{2}$ Department of Food Technology and Rural Industries, Bangladesh Agricultural University, Mymensingh-2202
}

\begin{abstract}
The study is concentrated with the role of inherent antioxidants content of selected mango varieties on the quality and shelf life of developed mango products. Three mango varieties as gutti, ashina, and langda and two mango products; mango bar and mango fruit drinks were used in this study. Antioxidant contents of three varieties of mango pulp and microbial loads of mango bar and mango fruit drinks were assessed. All three varieties contained vitamin $\mathrm{A}$, beta carotene, and vitamin $\mathrm{C}$ as an antioxidant and their contents were higher in gutti variety than other two varieties; Asina and Langda. Antioxidants were made an effective role to resist microbial load in the mango products. No microbial growth was observed within three months in the products (mango bar and mango fruit drink) of gutti mango variety except total plate count (TPC), which showed slight growth after four months of storage. The other two products from Asina and Langda were affected by microbial growth as TPC within one and two months consecutively. The study discloses that the antioxidant content of mango varieties had significant effect on the quality and shelf life in mango products.
\end{abstract}

Keywords: Antioxidant; Shelf-life; Mango varieties

\section{Introduction}

Antioxidants are chemicals (both naturally occurring and man-made) that can prevent or slow cell damage. Fruits and vegetables contain many antioxidant compounds including phenolic compounds, carotenoids, anthocyanins and tocopherols (Bartosz, 1997; Naczk and Shahidi, 2006). Antioxidants can also be produced artificially and consumed in supplement form. Antioxidants are one of the first lines of defense that the body employs to keep free radicals in check and prevent them from causing a domino effect of damage on other cells. Antioxidant compounds can "donate" electrons to unstable free radicals so they don't have to snatch electrons from unsuspecting nearby cells. Antioxidants can also help repair cell damage caused by free radicals. Studying the relationship between antioxidant status and disease has proven to be a highly profitable line of research. It has expanded our knowledge concerning the etiology of numerous diseases and the means by which they might be prevented. But it is essential to take a balanced perspective and avoid the danger of over-enthusiasm for the potential of antioxidants (Temple, 2000). Mango (Mangifera indica L.) is one of the most important commercial crops worldwide in terms of production, marketing and consumption (Ribeiro et al., 2007). The mango is indigenous to Bangladesh, India, Pakistan and Southeast Asia. The item is cultivated in many tropical regions and distributed widely in the world. Mangoes can be considered a good source of dietary antioxidants, such as ascorbic acid, carotenoids and phenolic compounds (Sheiber et al., 2000). Mango is one of the most extensively exploited fruits for food, juice, bar, chutney, color, making it a common ingredient in functional foods often called super fruits. Mango is a seasonal fruit and it is highly perishable. The improper handling, processing and preservation technique can losses large amount of mango in peak season in Bangladesh. The prevention of the losses of the seasonal surplus of mango could be possible by processing and preservation of them using proper techniques at farmer's level as well as industrial level. There are various techniques that will help the farmer to utilize the surplus fruits in peak season (Bose, 2000). The processing of mango into bar and drinks are the common techniques for utilizing the surplus fruits. The most common and convenient mode in which fruits are processed and preserved in the form of fruit juices/pulps (Ahmed, 2014). In Bangladesh, fruit bar

*Corresponding author e-mail: marufqc@gmail.com 
prepared from mango is commercially available. In laboratory, investigations were carried out to prepare fruit bars from banana mixed fruit bar (Karmokar, 2009) and pineapple (Emdad, 2014). On the other hand mango juice is prepared by diluting mango pulp and adding required amount of sugar, acidulants and preservatives. Both the products are susceptible to oxidation during storage due to sugar content. Hence, for better keeping quality antioxidant as well as preservative need to be added. Besides, addition of potassium metabisulphite in mango leather gave better sensory qualities and longer shelf-life. It is generally known that fruits are rich in antioxidants that help in lowering degenerative diseases. Thus, it is considered important to increase the antioxidant intake in the human diet and one way of achieving this is by enriching food with antioxidant. Processing food with antioxidant enrich raw materials are preferred to addition of pure antioxidants to it from economic point of view. It is reported that there are few mango varieties which are higher in antioxidant content compared to other varieties. Therefore, the present study was undertaken to evaluate antioxidant profile of selected mango varieties as well as to assess the effect of antioxidant on the shelf life of selected mango products prepared from those varieties.

\section{Materials and methods}

Samples of mango in three varieties like gutti, asina, langda are collected from various area of the country like southern part of country named Jessore, Northern part named Chapinawabgoanj, Eastern side of Bangladesh named Chittagong. All mangoes were mature and ripe. Average weights of the experimental mangoes were $180 \mathrm{~g}-200 \mathrm{~g}$ of gutti, $300 \mathrm{~g}-350 \mathrm{~g}$ of asina and $190 \mathrm{~g}-250 \mathrm{~g}$ of langda. All were checked visually and only defect free mangoes were allowed for study. Two products, dehydrated product named mango bar and mango fruit drink were considered to experiment.

\section{Sample preparation (mango pulp)}

Mangoes were washed by treated water, initially normal and finally hot water $\left(45^{\circ} \mathrm{C}\right)$. After peeling and deseeding the mangoes of three varieties (gutti, asina, and langda), these were kept in separate stainless steel vessel with covers. Then they were transferred into refiner having mesh-350 one by one to remove fibers from the mango pulp. Right after samples were transferred in the steam jacket kettle and heated to $95^{\circ} \mathrm{C}-100^{\circ} \mathrm{C}$ for 30 minutes to pasteurize the samples. Finally pulps were filled into screw cap bottles sealed and stored at room temperature for further use. Now some parameters like vitamin $\mathrm{A}$, beta carotene, vitamin $\mathrm{C}$, colour, and flavor are tested on these three separate mango pulps of gutti, asina and langda variety.

\section{Sample preparation of mango bar}

The prepared stocks of mango pulp of the three varieties was heated up to obtain the ${ }^{0}$ brix $28^{0}$ and poured by $4 \mathrm{~kg}$ in each tray into the three separate SS-trays. All trays were cleaned and greased by applying food grade paraffin oil on the surface of the trays. Then the trays with mango pulps of gutti, asina and langda were transferred into a drier for drying by $55^{\circ} \mathrm{C}-60^{\circ} \mathrm{C}$ for 48 hours and completion of dehydrating the first layer of the bar then again $4 \mathrm{~kg}$ of mango pulps of the experimental three varieties were poured on the trays and dried by using same temperature $\left(55^{\circ} \mathrm{C}-60^{\circ} \mathrm{C}\right)$ and time $(48$ hours) in the same drier for drying the second layer. After completion of drying the two layers of those products of three varieties were turned into one layer. Now they were sliced by SS-knife having size of length $8.0 \mathrm{~cm}$, width $2.0 \mathrm{~cm}$ and thickness $0.45 \mathrm{~cm}$ and again the slices of the mango bars were dried for further 24 hours in the drier till achieving the moisture $15 \%$. The prepared sliced bars were packed in the layered flexible foil which was made of PET (polyethylene terothalate), MPET (metalize polyethylene terothalate) and LLDPE (Linear low density polyethylene) and kept in an ambient temperature for further various experiments. Samples were analyzed for microbial loads at o, 30, 60, 90, 150, 180, 240 and 270 days.

\section{Sample preparation of mango fruit drink}

Mango pulp of three varieties like gutti, asina and langda were taken from stock and refined by refiner with mesh-350 separately to remove fibers and other foreign particles and preserved in three separate master vessel. In another three separate SS-vessel, juice ingredients like citric acid $4.94 \%$, sugar as syrup $13 \%$, mango emulsion $0.015 \%$, mango flavor $0.045 \%$, mango pulp $10 \%$ and water $72 \%$ were taken and blended for 30 minutes. Then the blended fruit drinks were transferred into three separate saucepans and heated them at $85^{\circ} \mathrm{C}-90^{\circ} \mathrm{C}$ for sterility the fruit drinks and filled in the cleaned and washed PET (polyethylene terrothalate) bottles and closed the filled bottles with plastic closures and kept in an ambient temperature for further study.

\section{Apparatus for analysis of vitamin A, beta-carotene and vitamin $C$}

For chemical test: Liquid Chromatography Mass Spectrometer (LCMS) (model no: LCMS-8040, origin: Shimadzu, Japan); Balance (model no: BSA 124S, origin: Sartorius scientific instruments (Beijing) Co, Ltd, China). Test parameters (vitamin A, Beta carotene and vitamin C) were tested by method AOAC. 


\section{Microbial apparatus and media description}

Microbial parameters as coliform, TPC, Yeast and Mold are tested. Eosin methyl blue (EMB) agar and MacConkey broth w/neutral red (HiMedia Laboratories Pvt. Ltd., India) for coliform; Plate count agar (HiMedia Laboratories Pvt. Ltd., India) for TPC; Potato dextrose agar (HiMedia Laboratories Pvt. Ltd., India) for yeast \& mold testing.

Methyl Red Indicator; Iodin; Methyl Orange; Ferroin Indicator Sol; Glycerol; Methylene Blue; Oil emersion; Chrystal violet; Safranin; Covacs Indole reagent; Vogusproscure; MIU Medium; Lactophenol cotton blue; Microbial testing of parameters (Coliform, TPC, yeast and mould) were tested by using the method BDS ISO 4832:2009, BDS ISO 4833:2009 and ISO 21527-1: 2008 consecutively.

\section{Statistical analysis}

All the experiments were carried out triplicates. The experimental data were compiled, tabulated and analyzed. Data analysis was carried out using commercial statistical software Stat graphics Centurial XVI.

\section{Results and discussion}

Antioxidant content of different variety of mango

The pulp prepared from three varieties of mango was analyzed for vitamin $\mathrm{A}$, beta-carotene and vitamin $\mathrm{C}$ and the results are shown in Table I.

As shown in Table I, irrespective of mango variety beta-carotene is the dominant antioxidant in mango followed by vitamin $\mathrm{A}$ and vitamin $\mathrm{C}$ is the least dominant components. When comparing among variety, gutti contained the highest amount of vitamin A $(45 \mu \mathrm{g} / 100 \mathrm{~g})$, closely followed by langda $(40 \mu \mathrm{g} / 100 \mathrm{~g})$ whereas asina contained the lowest amount of vitamin A $(33 \mu \mathrm{g} / 100 \mathrm{~g})$. In case of beta carotene, the content was the highest in gutti variety, followed by Asina and then followed by Langda. The same trend was observed in case of vitamin C. Due to close value of beta carotene, the color of pulp of all varieties remained yellowish and hardly able to differentiable with naked eyes. Lim et al. (2007) reported antioxidant activity of different tropical fruits like mango, jackfruit, papaya, banana etc. They reported the mango as a potential source of antioxidant.

Correlation with mango pulp antioxidants and microbial count in Mango bar

Kinetics of microbial counts in mango bar prepared with mango pulp from three mango varieties is Shown in Figure 1.

As shown in Figure 1, different microbial counts with storage was highly correlated with the mango variety. As shown in Figure 1(a), the least microbial count was observed in mango bar prepared with gutti variety. Except TPC, no other microbial growth was observed. Even after three months of storage, TPC growth was started and its count was increased with quite slow rate up to 9 month of storage. During this storage, no other microbes like coliform, yeast and mold were observed. In case of mango bar prepared from Asina variety, microbial growth was started from very beginning of storage and their population were constantly increased with

Table I. Antioxidant profile of mango pulp prepared from three mango varieties (Gutti, Ashina, Langda)

\begin{tabular}{cccccccccc}
\hline Sample & \multicolumn{3}{c}{ Vitamin A $(\mu \mathrm{g}$} & $/ 100 \mathrm{~g}) \pm \mathrm{RSD}$ & \multicolumn{2}{c}{ Beta carotene } & $(\mu \mathrm{g} / 100 \mathrm{~g})$ & $\pm \mathrm{RSD}$ & \multicolumn{3}{c}{ Vitamin C } & $(\mu \mathrm{g} / 100 \mathrm{~g})$ & $\pm \mathrm{RSD}$ \\
\hline & Gutti & Ashina & Langda & Gutti & Ashina & Langda & Gutti & Ashina & Langda \\
Sample - & $45 \pm 0.12$ & $33 \pm 0.05$ & $40 \pm 0.08$ & $480 \pm 0.85$ & $420 \pm 0.72$ & $410 \pm 0.69$ & $32 \pm 0.05$ & $25 \pm 0.04$ & $20 \pm 0.03$ \\
Sample -2 & $45 \pm 0.11$ & $32 \pm 0.05$ & $42 \pm 0.09$ & $475 \pm 0.76$ & $420 \pm 0.71$ & $420 \pm 0.71$ & $33 \pm 0.06$ & $24 \pm 0.03$ & $21 \pm 0.04$ \\
Sample -3 & $44 \pm 0.90$ & $34 \pm 0.06$ & $41 \pm 0.08$ & $480 \pm 0.84$ & $425 \pm 0.74$ & $415 \pm 0.70$ & $32 \pm 0.04$ & $24 \pm 0.04$ & $20 \pm 0.03$ \\
Sample -4 & $45 \pm 0.11$ & $33 \pm 0.07$ & $40 \pm 0.07$ & $470 \pm 0.75$ & $430 \pm 0.76$ & $410 \pm 0.68$ & $31 \pm 0.04$ & $25 \pm 0.05$ & $19 \pm 0.02$ \\
Sample -5 & $46 \pm 0.15$ & $33 \pm 0.06$ & $42 \pm 0.08$ & $480 \pm 0.83$ & $420 \pm 0.70$ & $410 \pm 0.67$ & $32 \pm 0.05$ & $25 \pm 0.04$ & $20 \pm 0.03$ \\
Sample -6 & $46 \pm 0.14$ & $32 \pm 0.05$ & $40 \pm 0.08$ & $475 \pm 0.75$ & $430 \pm 0.77$ & $410 \pm 0.66$ & $34 \pm 0.07$ & $25 \pm 0.05$ & $22 \pm 0.04$ \\
Sample -7 & $45 \pm 0.15$ & $34 \pm 0.06$ & $41 \pm 0.09$ & $476 \pm 0.77$ & $425 \pm 0.75$ & $420 \pm 0.72$ & $32 \pm 0.06$ & $26 \pm 0.06$ & $21 \pm 0.03$ \\
\hline
\end{tabular}

RSD: Relative Standard Deviation 

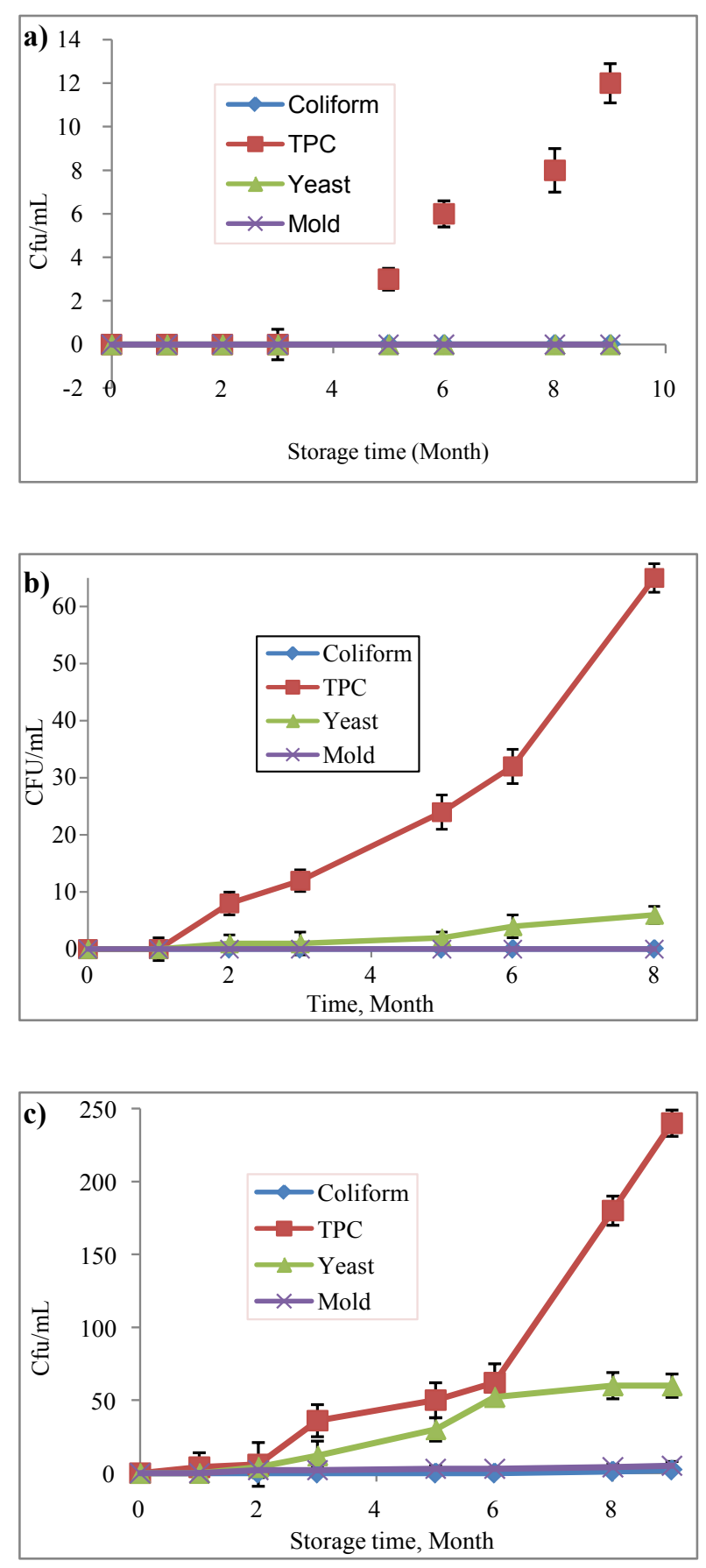

Fig. 1. Kinetics of microbial growth in mango bar prepared from pulp of (a) Gutti variety (b) Asina and (c) Langda increasing storage period up to end of storage study (Figure 1b). Up to first 2 months, TPC growth was slow and then its rate was increased and this trend was continued up to 6 months and then this rate increased abruptly. However, mold and coliform growth remained quite slow. A significant growth rate was observed in case of yeast. In case of mango bar prepared from Langa variety, a moderate growth of TPC and yeast was observed. This growth is slightly high compared to that in mango bar from gutti variety and pronounced low compared to that in mango bar from Asina variety.

This is mainly due to antioxidant content in pulp from where mango bar. As shown in Table I, gutti variety contained the highest amount of antioxidant followed by Asina and the lowest amount in Asina. Consequently, mango bar prepared from gutti variety inhibited potentially the growth of differently microorganism. On the other hand, antioxidant content of Asina variety and consequently its effect on the growth of microorganism was also neglected. The antimicrobial potential of many antioxidants was reported by many researchers (Nusrat, 2015). Jagtap et al., (2010) reported the antioxidant capacity of mango pulp and showed that its elevated content helped to increase the shelf life of mango pulp.

Correlation with pulp antioxidants and microbial count in Mango fruit drink

Kinetics of microbial counts in mango drinks prepared with mango pulp from three mango varieties is shown in Figure 2.

As shown in Figure 2, different microbial counts with storage in mango drinks showed the same behaviour as that of mango bar, i.e. the content of antimicrobial components varied with mango variety and accordingly inhibited growth of microbes. As shown in Figure 2(a), the least microbial count was observed in mango drinks prepared with gutti variety. Except TPC, any other microbial growth was hardly observed. Even TPC growth was started after three months of storage and its count was increased at quite slow rate up to 9 month of storage. During this storage, no other microbes like coliform, yeast and mold were observed. In case of mango drinks prepared from Asina variety, except coliform, all other microbial counts were started from the very beginning of 

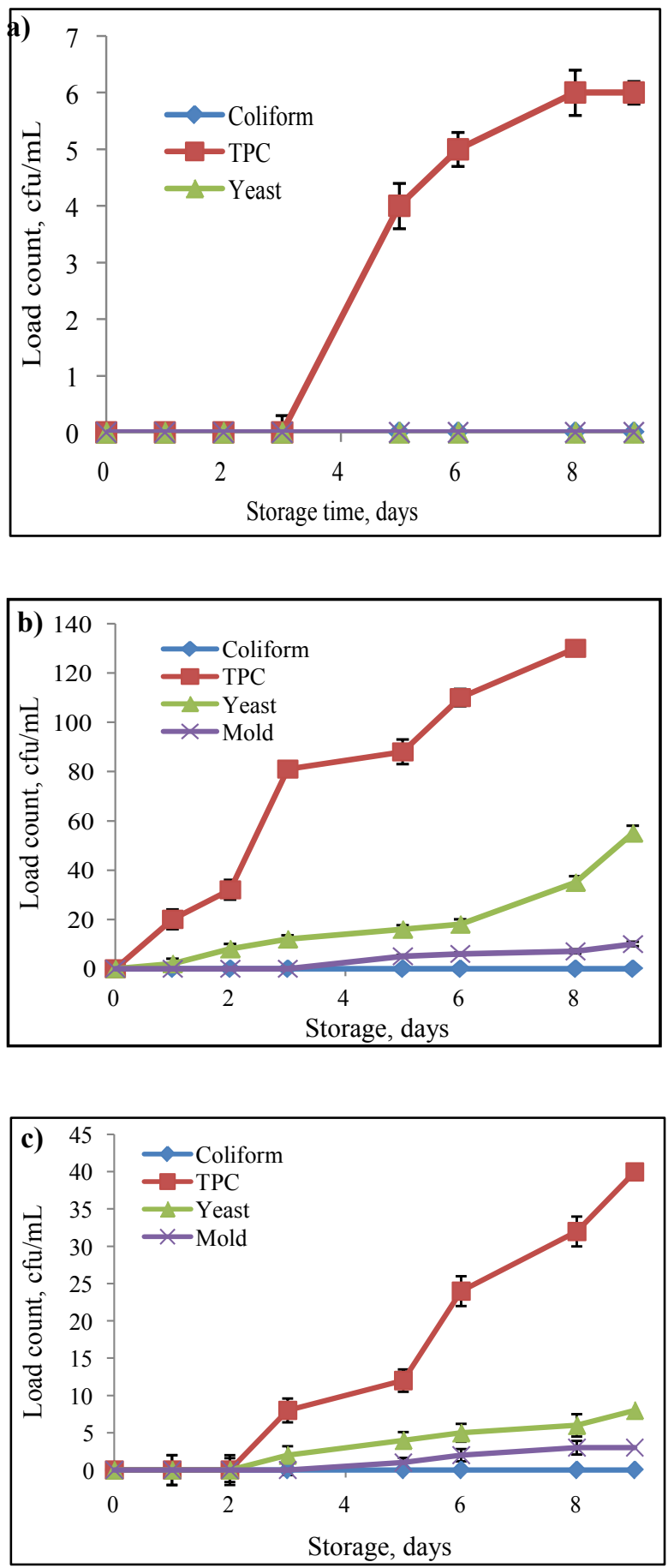

Fig. 2. Kinetics of microbial growth in mango drinks prepared from pulp of (a) Gutti variety (b) Asina and (c) Langda storage and their population were constantly increased with increasing storage period up to end of storage study (Figure $2 b)$. Up to first 3 months, TPC growth was slow and then its rate was increased at quite faster. However, no coliform growth was observed throughout the storage period even though growth of mold exhibited at a quite slow rate. In case of mango drinks prepared from Langda variety, a moderate growth of TPC and yeast was observed. This growth is slightly high compared to that in mango bar from gutti variety and pronounced low compared to that in mango drinks from Asina variety. No coliform growth was also observed in mango drinks prepared with Langda variety thoughout the storage period.

As shown in Table I, gutti variety contained the highest amount of antioxidant followed by Asina and the lowest amount in Asina. Consequently, mango drinks prepared from gutti variety inhibited potentially the growth of differently microorganism. On the other hand, antioxidant content of Asina variety was low and consequently its inhibition capacity on the growth of microorganism was also neglected. The antimicrobial potential of many antioxidants was reported by many researchers (Nusrat, 2015). Jagtap et al., (2010) reported the antioxidant capacity of mango pulp and showed that its elevated content helped to increase the shelf life of mango pulp.

\section{Conclusion}

The work exposes that the antioxidant content of mango has an enormous effect on the quality and shelf life of mango products. In this study gutti variety of Bangladesh contains the highest antioxidant content and hence of products like mango bar and mango fruit drink developed from this variety showed the best quality and the longest shelf life compared to ashina and langda varieties.

\section{References}

Ahmed B, Uddin MB and Jubayer MF (2014), Extraction and standardization of selected fruit juices by enzymatic process, Peak Journal of Food Science and Technology 2(2): 18-27.

Bartosz S (1997), Oxidative stress in plants, Acta Physiologieu Plantorum 19: 47-64.

Bose S (2000), Studies on the development of mixed mango-Pineapple Juice, MS Thesis, Dept. of Food Technology and Rural Industries, Bangladesh Agricultural University, Mymensingh. 
Emdad (2014), Kinetics of non-enzymatic browning of mango bar, MS Thesis, Dept. of Food Technology and Rural Industries, Bangladesh Agricultural University, Mymensingh.

Hossain AA and Jahan R (2014), Studies on the Processing of mixed fruit bar from mango, banana and papaya, Project Work, Department of Food Technology and Rural Industries, Bangladesh Agricultural University, Mymensingh.

Jagtab UB, Shrimant and Bapat VA (2010), Evaluation of antioxidant capacity and phemol content in jackfruit fruit pulp, Plant Foods Human Nutrition 65: 99-104.

Karmokar P (2009), Studies on the Processing of mixed fruit bar from mango, pineapple, papaya, MS Thesis, Dept. of Food Technology and Rural Industries, Bangladesh Agricultural University, Mymensingh.

Lim YY, Lim TT and Tee JJ (2007), Antioxidant properties of several tropical fruits: A comparative study, Food Chemistry 103: 1003-1008.

Naczk M, and Shahidi F (2006), Phenolics in cereals, fruits and vegetables: occurrence, extraction and analysis, Journal of pharmaceutical and Biomedical Analysis 41: $1523-1542$.
Nushrat Y (2014), Effects of extraction methods on the antioxidant activity of tarmarind seed, $M S$ Thesis, Dept. of Food Technology and Rural Industries, Bangladesh Agricultural University, Mymensingh.

Ribeiro SMR, Queiroz JH, de Queiroz MELR, Campos FM and Sant'Ana HMP (2007), Antioxidant in mango (Mangifera indica L.) pulp, Plant Foods for Human Nutrition 62(1): 13-17.

Reskanich D, Ziegler RG, Michaud DS, Giovannucci EL, Speizer FE and Willett WC (2000), Prospective study of fruit and vegetable consumption and risk of lung cancer among men and women, Journal of the National Cancer Institute 92: 1812-1823.

Shieber A, Ulrich W and Carle R (2000), Characterization of polyphenols in mango pure concentrate by HPLC with diode array and mass spectrometric detection, Innov Food Sci Emerg Technol 1: 161-166.

Temple NJ (2000), Antioxidants and disease: more questions than answers, Nutrition Research 20(3): 449-459

Received: 21 May 2017; Revised: 06 July 2017;

Accepted: 31 July 2017. 